\title{
Deep UV laser-induced fluorescence for pharmaceutical cleaning validation
}

\author{
Krishnakumar Chullipalliyalil*, Liam Lewis, Michael A. P. McAuliffe \\ Center for Advanced Photonics and Process Analysis (CAPPA), Cork Institute of Technology, \\ Cork, Ireland. \\ *Correspondence: krishna.cp@cit.ie
}

\section{Supporting information}

\section{Table of Contents}

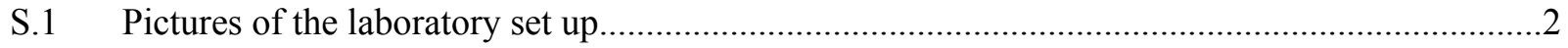

S.2 Fluorescence spectra of APIs and detergents measured using configuration 1 ..........................

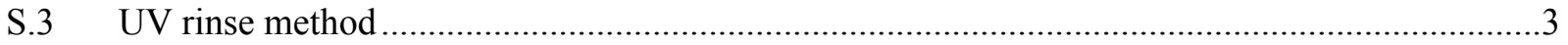

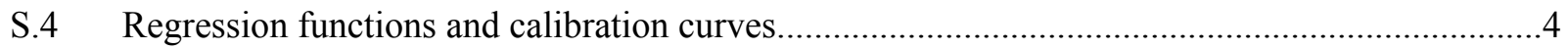

S.5 Fluorescence and IR absorption spectra of APIs on different substrates...................................6 


\section{S.1 Pictures of the laboratory set up}
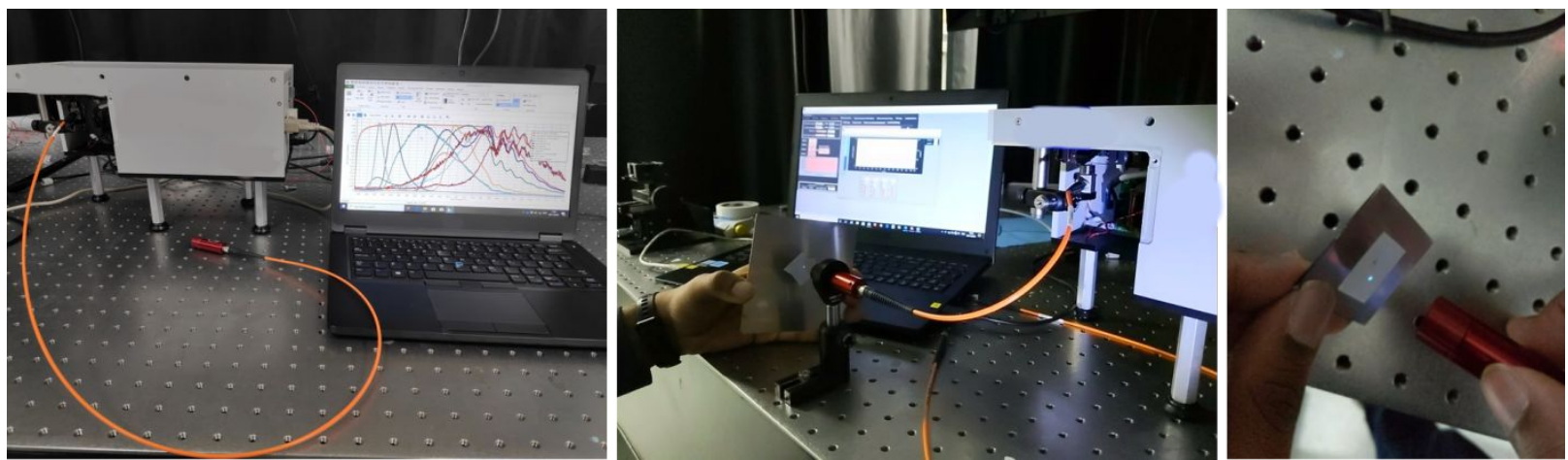

Figure S1 Modified Photon systems mini PL DUV spectrometer with fiber probe (configuration 2)
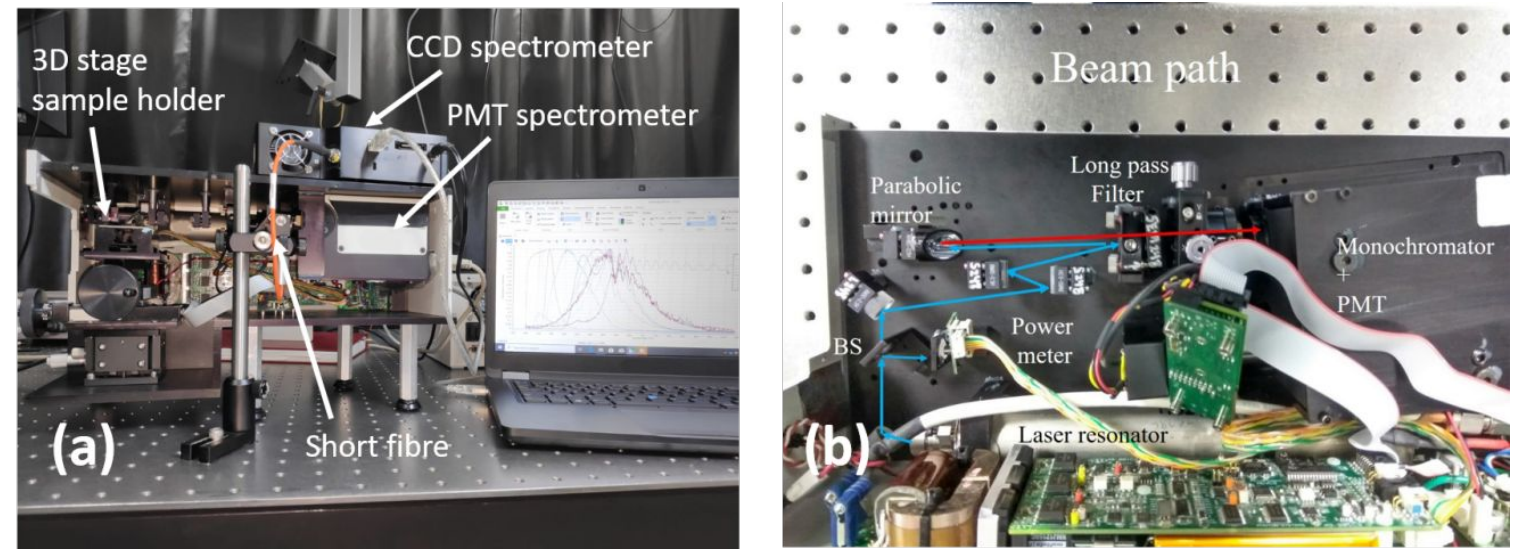

Figure S2 Laboratory set up of DUV measurements (a) Open side view of configuration 1. (b) Beam path in photon systems DUV spectrometer
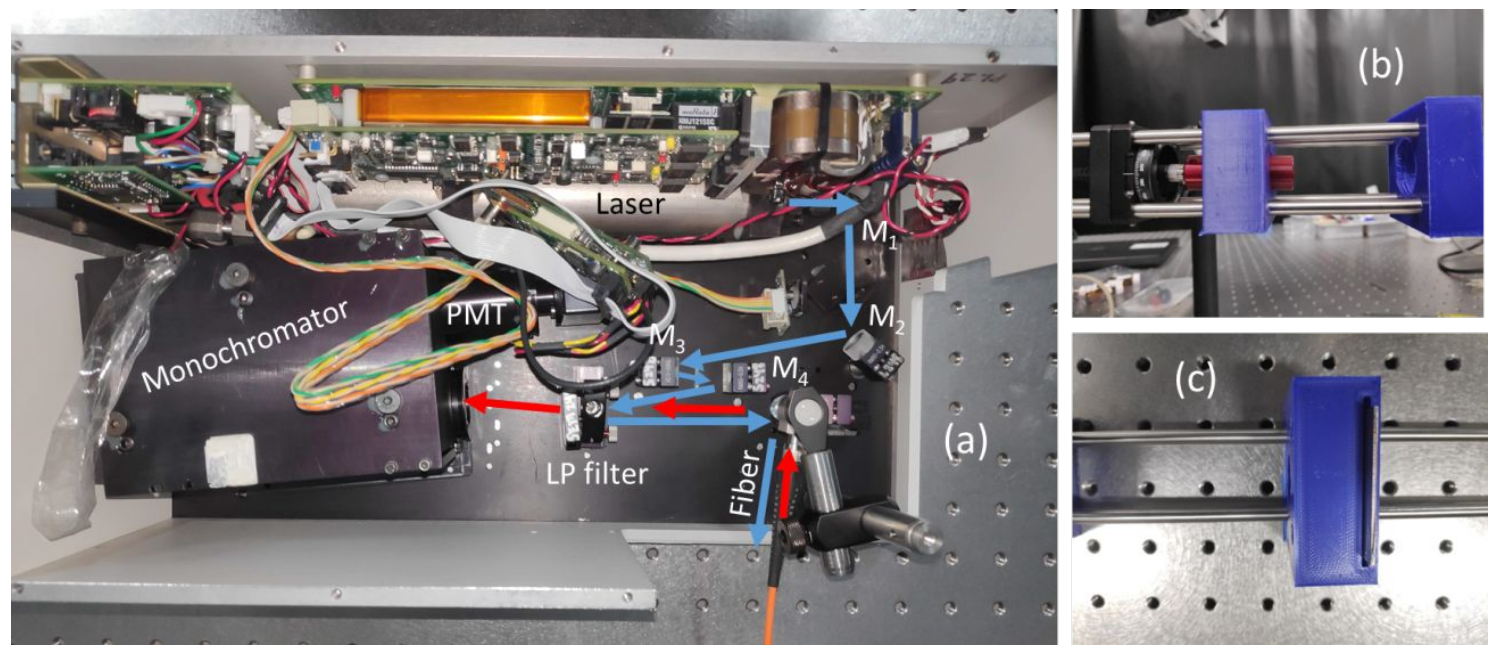

Figure S3 (a) Beam path in photon systems DUV spectrometer with fiber probe (configuration 2) (b) Sample holder in configuration 2. (c) Top view of the sample holder in configuration 2. 


\section{S.2 Fluorescence spectra of APIs and detergents measured using configuration 1}

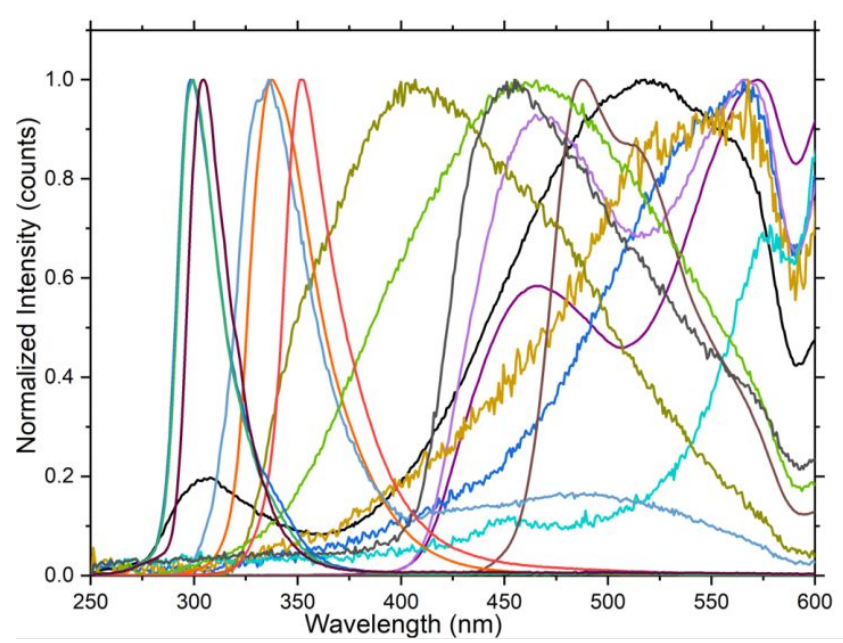

(a)

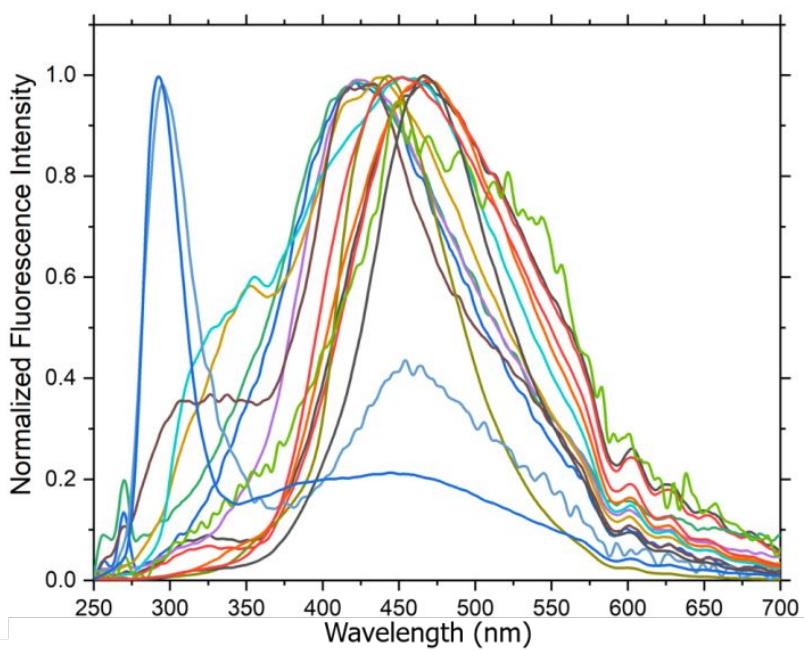

(b)

Figure S4 (a) Normalized fluorescence spectra of different APIs measured using CCD in configuration 1 on steel substrates. (b) Normalized fluorescence spectra of detergents measured using CCD in configuration 1 on steel substrates. The strong Raman signal from the detergents can also be seen below $280 \mathrm{~nm}$.

\section{S.3 UV rinse method}

\section{Estimation of the concentration of API stains using the UV absorption}

A dry swab is prewetted with solvent from a vial premeasured with $2 \mathrm{~mL}$ of the diluent (methanol in this case). The wet swab is then used to wipe the stain in a standard method (as mentioned in Haider et al. ${ }^{28}$ ) and placed back in the solvent in the vial. The vial is sonicated for five minutes. The solution is transferred into a quartz cuvette and the UV absorption spectra are measured. The absorbance values were then used to retrieve the original concentrations using a calibration curve. The calibration curve was prepared by measuring $5 \mu 1$ of the drug solutions $(10,20,30 \ldots, 100$ $\mu \mathrm{g} / \mathrm{mL}$ ) in methanol for $2 \mathrm{ml}$ total volume.

The most distinctive absorption band for paroxetine was at $292 \mathrm{~nm}$, and hence the same was used for retrieving the concentration values of the swabs. For fluticasone, the absorption band at $233 \mathrm{~nm}$ was used for the estimation. The calibration curves obtained for both drugs on steel substrates and the retrieved values are shown in Figure (a) and Figure (b). The stains for both API's having concentrations below $2.5 \mu \mathrm{g} / \mathrm{cm}^{2}$ appear transparent on the substrates upon examination using ambient light and hence are below the visual detection limit. 


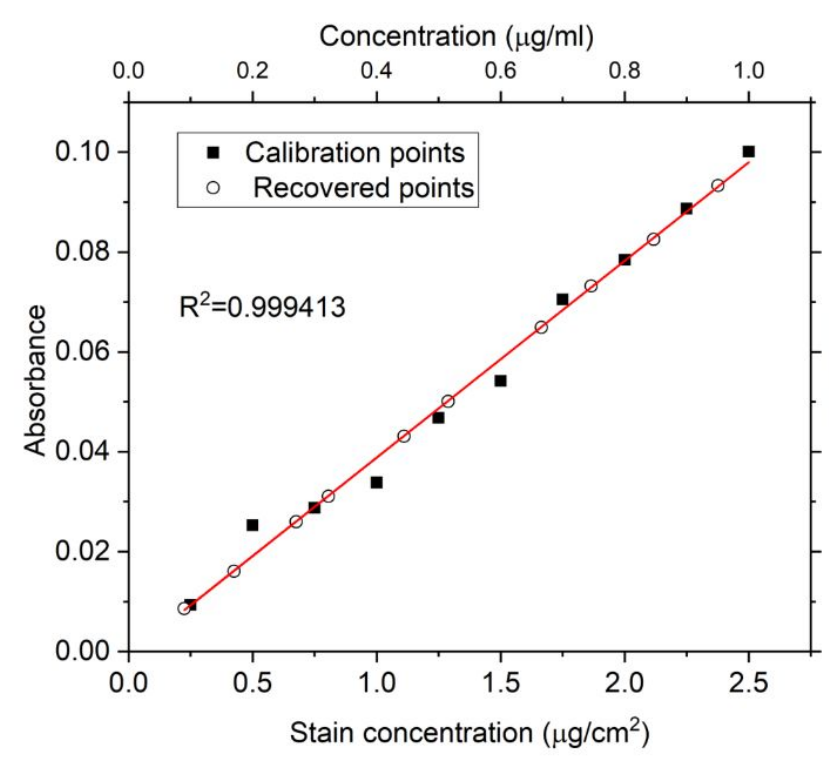

(a)

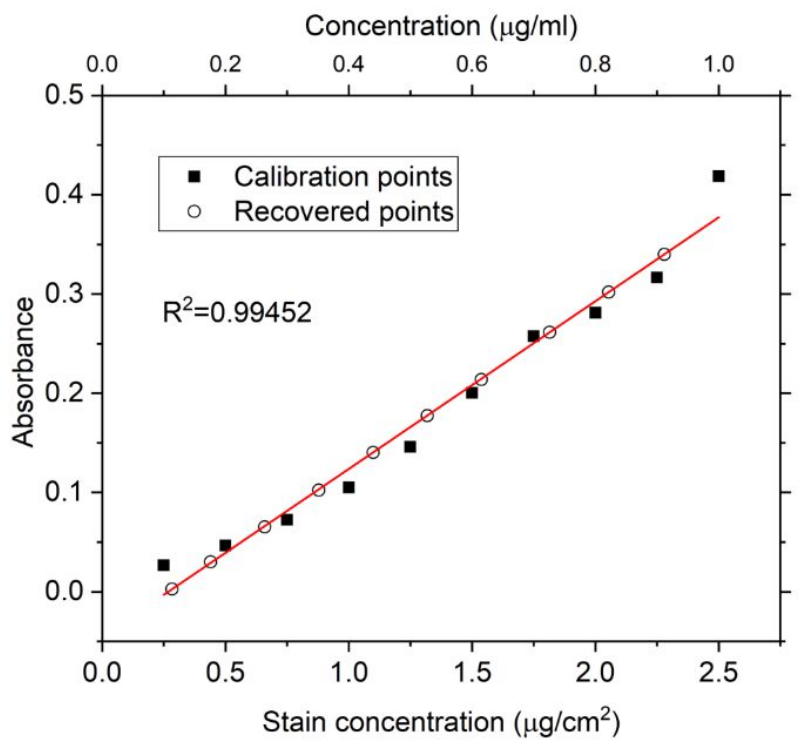

(b)

Figure S5: UV-Vis absorption calibration curves for (a) Fluticasone propionate and (b) paroxetine made using standard solutions (red curve). Black squares represent calibration points, and circles represent recovered concentrations of the stains.

\section{S.4 Regression functions and calibration curves}

$\left(\mathrm{C}_{\mathrm{F}}, \mathrm{C}_{\mathrm{P}}=\right.$ concentration of fluticasone and paroxetine, $\mathrm{I}_{\mathrm{F}}, \mathrm{I}_{\mathrm{P}}=$ Intensity of fluorescence from Fluticasone and Paroxetine $)$

\begin{tabular}{|l|l|l|l|}
\hline Substrate & Regression function & $\mathbf{R}^{2}$ & $\begin{array}{l}\text { Lowest concentration } \\
\text { measured }\left(\boldsymbol{\mu g} / \mathbf{c m}^{2}\right)\end{array}$ \\
\hline Steel & $\mathrm{I}_{\text {Fluticasone }}=1037.03 \mathrm{C}_{\mathrm{F}}+7.90$ & 0.9564 & 0.21 \\
\hline & $\mathrm{I}_{\text {Paroxetine }}=494 \mathrm{C}_{\mathrm{P}}+1094$ & 0.9766 & 0.19 \\
\hline Blue glass & $\mathrm{I}_{\text {Fluticasone }}=2360 \mathrm{C}_{\mathrm{F}}+1328$ & 0.9826 & 0.23 \\
\hline & & & \\
\hline & $\mathrm{I}_{\text {Paroxetine }}=173 \mathrm{C}_{\mathrm{P}}+78$ & & \\
\hline
\end{tabular}

Table S1. Regression functions for Intensity values at different substrates 


\section{Calibration curves for DUV configuration 1 (without fiber)}

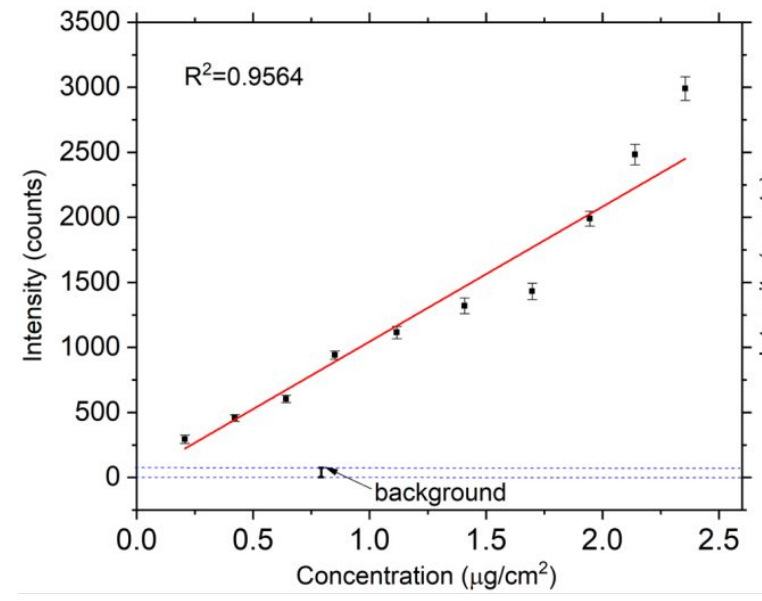

(a)

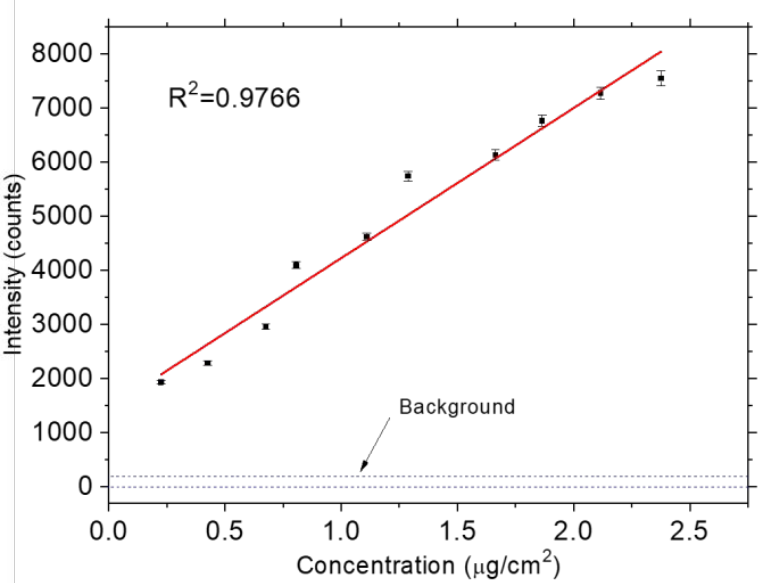

(b)

Figure S6 (a)Calibration curve developed for the region $0.2-2.5 \mu \mathrm{g} / \mathrm{cm}^{2}$ in the fluticasone stain for the instrument using the intensity at fluorescence maximum $\left(\lambda_{\text {em.max }}=395 \mathrm{~nm}\right)$. (b) Calibration curve developed for the region $0.2-2.5 \mu \mathrm{g} / \mathrm{cm} 2$ for the instrument using the intensity at fluorescence maximum $(\lambda \mathrm{em} \cdot \mathrm{max}=355 \mathrm{~nm})$. The standard errors for each measurement are also shown.

\section{Calibration curves for DUV configuration 2 (with fiber in place)}

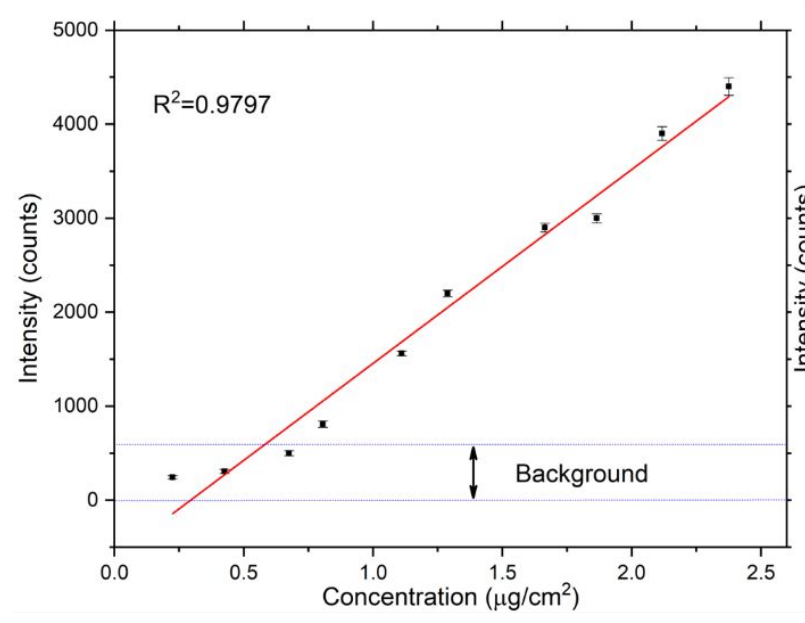

(a)

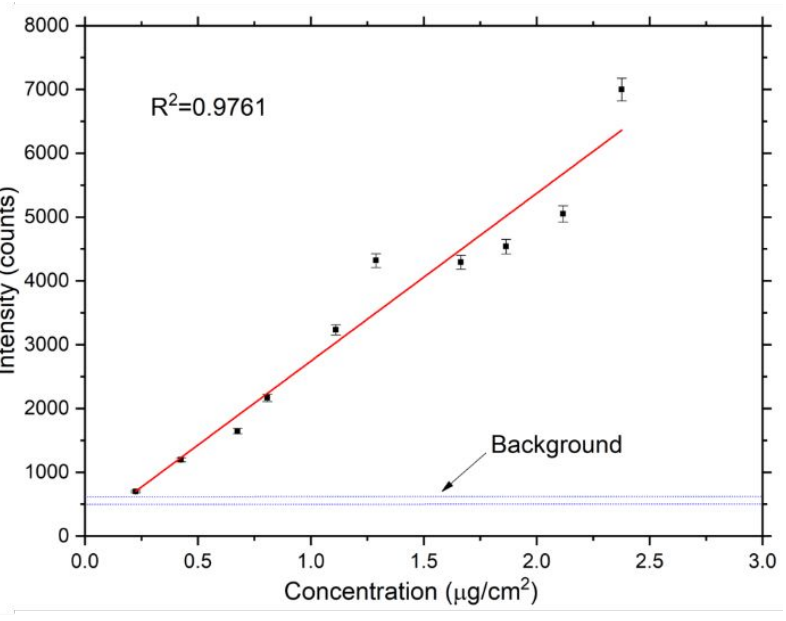

(b)

Figure S7 Calibration curve for (a) Fluticasone and (b) Paroxetine with the fiber in place (configuration 2). The acquisition time for (a) is $\approx 20 \mathrm{~min}$ and (b) is $\approx 12 \mathrm{~min}$. (Both data are obtained from average fluorescence at 10 points). The standard errors for each measurement are also shown.

Choice of standard error: Even though the stains are of trace concentrations, there are regions within the stain that vary in concentration (even to a factor of 1/100th). The fluorescence from the API induced by the laser at the mentioned wavelength of excitation is so sensitive that even the slightest of changes in concentration bring about huge variation in the reading. After averaging, we had to account for a large 
variance (which indicates the higher sensitivity of the instrument). The representation of the standard deviation did not justify how well the instrument could identify low concentrations after averaging all the independent measurements. While the standard deviation illustrates the spread and variability of the measurement, we were interested in the precision of the mean between different concentrations. Hence the decision to chose standard error over the standard deviation.

\section{S.5 Fluorescence and IR absorption spectra of APIs on different substrates}

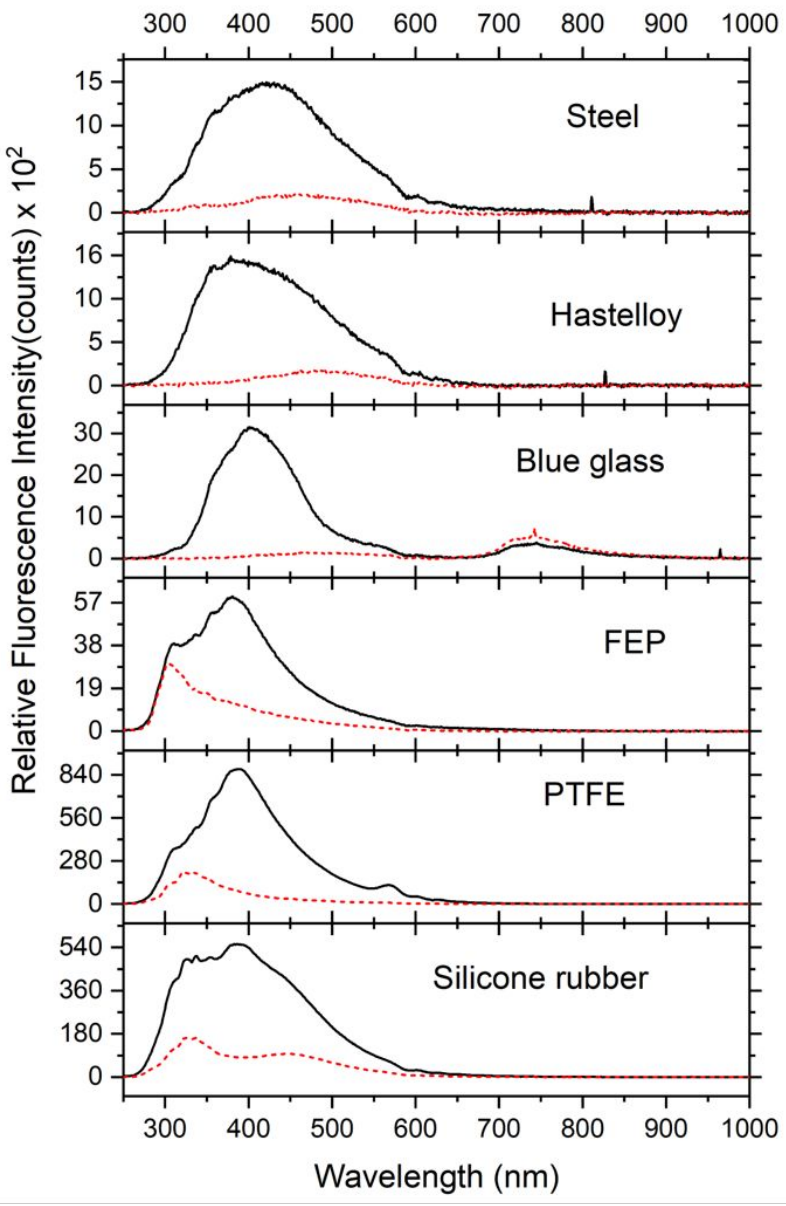

(a)

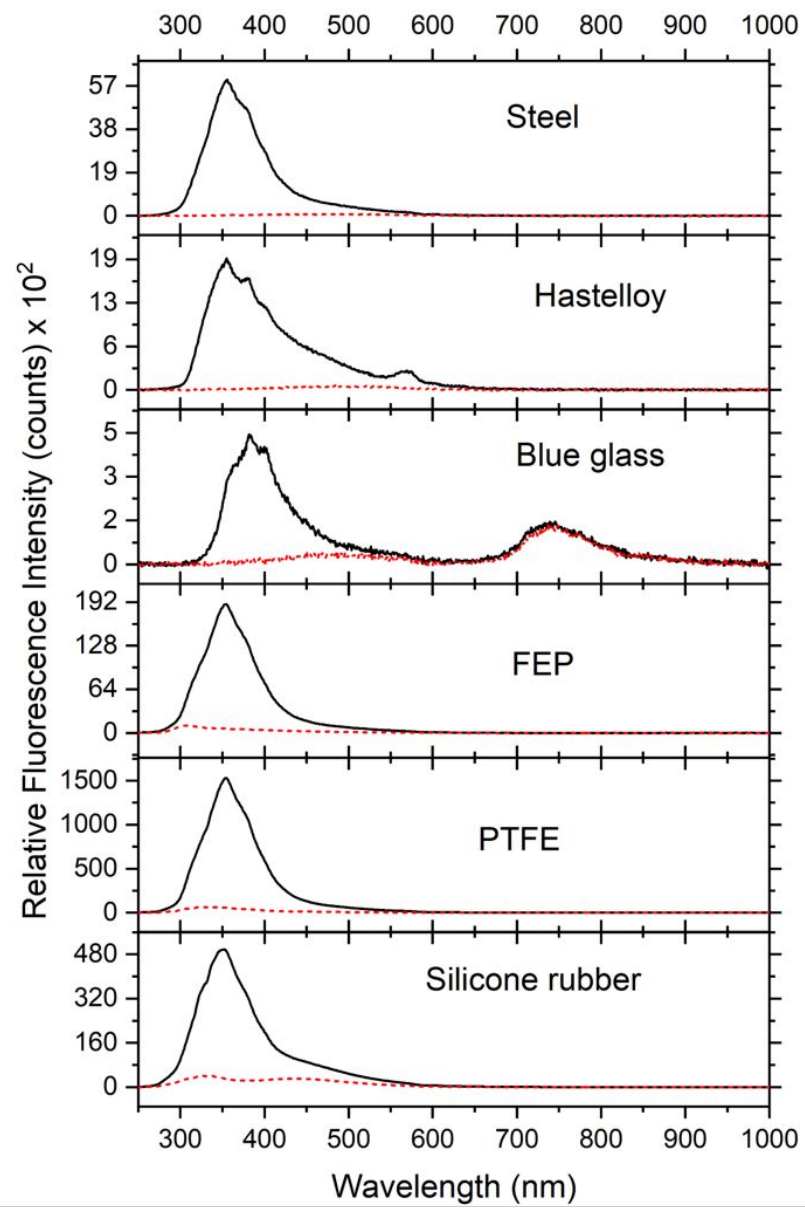

(b)

Figure S8. Effect of background on fluorescence measurement from the stain of (a) fluticasone at $\approx 2.38$ $\mu \mathrm{g} / \mathrm{cm}^{2}$ and (b) Paroxetine at $\approx 2.32 \mu \mathrm{g} / \mathrm{cm}^{2}$ (exposure time $=10 \mathrm{~s}$ for both) on different substrates.

Figure S8 shows the fluorescence spectra of both APIs in different substrates. The black curves represent the fluorescence from the APIs, and the red dotted curve represents the corresponding background fluorescence from the substrate. 


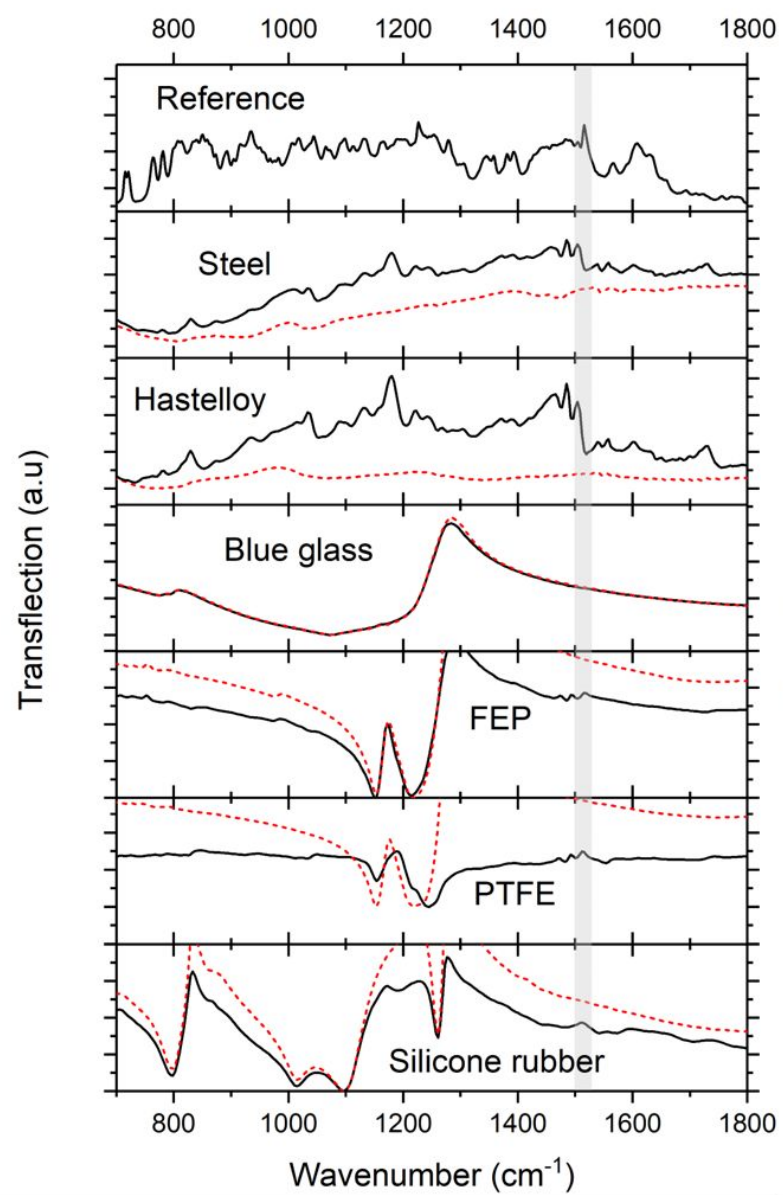

(a)

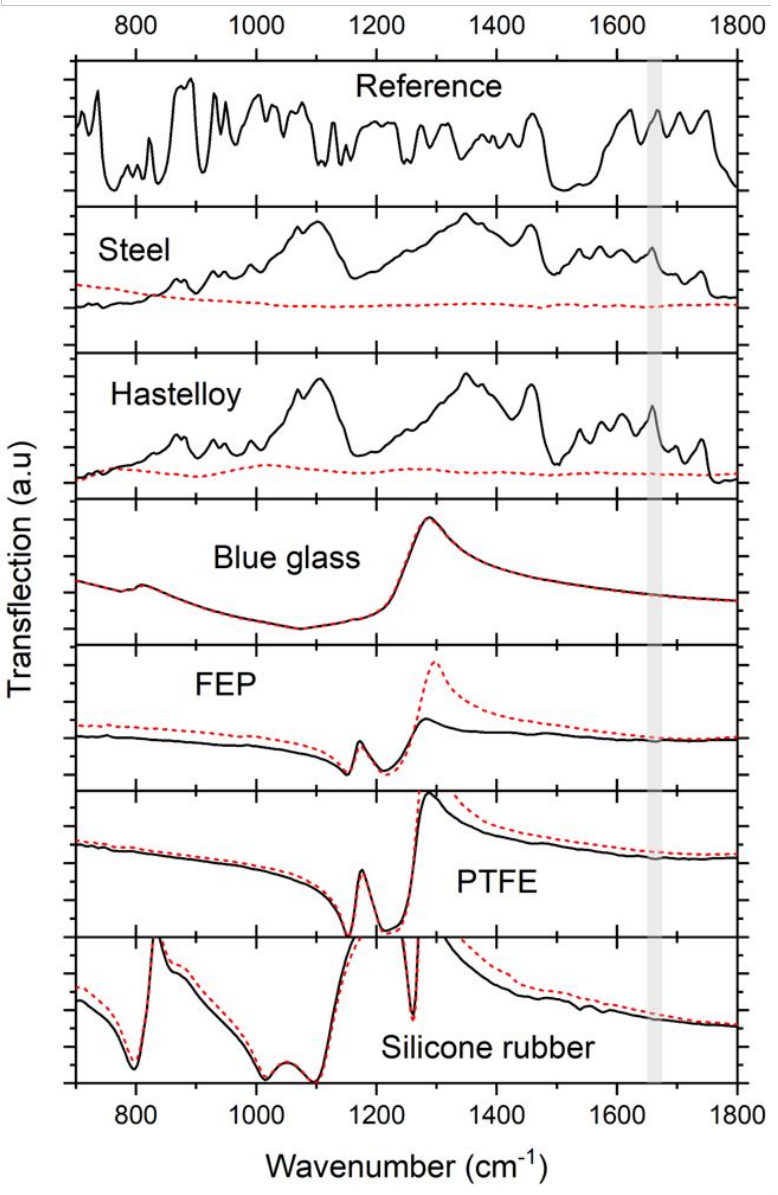

(b)

Figure S9. Background corrected MIR absorption (black curves) from (a) fluticasone at $\approx 2.38 \mu \mathrm{g} / \mathrm{cm}^{2}$ and (b) Paroxetine at $2.32 \mu \mathrm{g} / \mathrm{cm}^{2}$ (acquisition times for both is $\approx 16 \mathrm{~s}$ ) on different substrates.

Figure S9 shows the MIR absorption curves of both APIs in different substrates. (black lines) The corresponding background spectra from the substrates are shown in red dotted curves. The vibrational band used for comparison is shown in the shaded region. The reference sample used is powdered API in both cases. For the polymer tubing substrates, the background makes the vibrations from the API hardly distinguishable. 